\title{
The Transnational Dimensions of Science, Technology, and Medicine in Modern China
}

\section{Introduction}

\author{
Danian $\mathrm{Hu}$ 胡大年
}

China's impressive scientific accomplishments in recent years, such as Tu Youyou's 2015 Nobel Prize in Physiology or Medicine, the dominance of the Chinese Academy of Sciences (CAS) at the top spot in the Nature Index Global Top 100 for the last seven years, and the newly completed construction of the BeiDou Navigation Satellite System, have aroused widespread public interest in the contemporary Chinese development of science, technology, and medicine. This intense attention has in turn also triggered various myths, often based on misunderstanding or ignorance of relevant historical development, which calls for more and more thorough historical research. Hoping to shed some light on Chinese scientific development, we, a group of historians of science in Canada, China, Singapore, and the United States, have joined hands to present this special issue and explore "The Transnational Dimensions of Science, Technology, and Medicine in Modern China." In this issue, each of the six contributors presents a fresh and original case study concerning twentieth-century Chinese developments, covering topics such as the emergence of modern physics research in China, gender in science education, innovative mechanical study of phonetics, mathematicians and mathematics at the juncture of the country's great historical transition, politics and knowledge transmission, and knowledge exchanges under the Chinese political system. This issue does not aim to offer a comprehensive picture of Chinese scientific development in the last century. Rather, as tossing a minnow might lure a whale, we hope this special issue will attract more historians to devote their attention to the field, leading to more profound historical studies of relevant Chinese developments over the twentieth century. By reviewing the long and bumpy roads to recent successes, we hope to not only uncover overlooked roots of 
recent triumphs, but also draw important lessons from past setbacks.

This special issue begins with Danian Hu's article on physics study at Yenching University. It carefully examines the history of the short-lived and completely overlooked Physics Department in the Premedical School of Peking Union Medical College (PUMC) and, in particular, looks into the Master of Science (MS) program in the Department of Physics at Yenching University, which, founded in 1927, was the first graduate program in physics in China. Hu argues that it is this MS program that transformed the Yenching Department of Physics from a largely premedical training center serving the PUMC into a prominent cradle of Chinese physics research. Hu's paper not only introduces in detail the first four chairmen of the Yenching Department and their contributions, but also discloses the unique role played by the Rockefeller Foundation via the China Medical Board and the PUMC in the development of the department.

The second article by Grace Yen Shen explores both the personal and transnational dimensions of local science education and study abroad for China's pioneering generation of women in science. By focusing on women's unique calculus of risk and reward, the article not only distinguishes Chinese women's experiences from those of their male counterparts, but also demonstrates the special contours of the Chinese case within the global advancement of women in science. Shen argues that taking women's choices and strategies seriously reminds us not to consider their scientific pursuits exclusively in terms of developmental milestones in Chinese science; instead it directs our attention to the complex ways that scientific ambitions forced individuals - both male and female - to reimagine their personal and intellectual goals as they navigated shifting social norms and expectations.

The third article by Chen-Pang Yeang examines a specific case where the linguist Chao Yuen Ren applied mechanical means to his phonetic studies. This case demonstrates that Chao's machines not only provided a new method of observation, but also altered the theoretical understanding of certain fundamental categories in Chinese phonology, such as tones. Yeang argues that Chao did not aim to replace human perception with automatic mechanisms in empirical investigations. Rather, the use of machines in his research called for an active and engaged scientific persona.

The fourth paper by Zuoyue Wang and Guo Jinhai reconstructs the visits of Chinese mathematicians Shiing-shen Chern 陈省身 (Chen Xingshen) and Hua Luogeng 华罗庚 (Loo-Keng Hua) to the Institute for Advanced Study in Princeton (IAS) in the United States in the 1940s, and examines in particular their interactions with Oswald Veblen and Hermann Weyl, two leading mathematicians at the IAS. They argue that Chern's and Hua's motivations and choices, in regard to their transnational movements between China and the United States, were more nuanced and multifaceted than what is presented in existing accounts, and that both sociopolitical and personal-professional 
factors shaped their decisions. The paper further uses Chern's and Hua's experiences to demonstrate the importance of transnational scientific interactions for the development of twentieth-century science in China, the United States, and elsewhere.

The fifth article by Fang Xiaoping examines the origin, compilation, and circulation of A Barefoot Doctor's Manual (Chijiao yisheng shouce 赤脚医生手册) and explores the relationship between medical politics and knowledge transmission during the first thirty years of the People's Republic of China and the impact this had on the global promotion of Chinese medicine. Fang argues that the publication of A Barefoot Doctor's Manual embodied a public-oriented mode of knowledge transmission and demonstrated the impact of politics on medicine and health in the context of resource scarcity and low literacy. China's geopolitical change, the West's pursuit of alternative approaches to medicine and health, and the World Health Organization's concern with health universality and equity contributed to the translation and circulation of this manual and facilitated the global dissemination of Chinese medicine. The paper thus makes both empirical and theoretical contributions to the study of the relationship between medical politics and knowledge transmission in China.

The sixth and final paper, by Sigrid Schmalzer, uses the case of the Sino-Albanian Friendship Trees to examine the significance and limits of transnational scientific exchange in China during the 1960s and 1970s. Schmalzer finds that, although the olive trees served as symbols of international friendship and scientific exchange, knowledge about olive trees produced and circulated in the PRC reflected science in context (i.e. science within the national-level political context of 1960s-1970s China) more than knowledge in transit (i.e. the transnational circulation of knowledge). She argues that the importation of olive trees from Albania ended up offering a new application for Chinese agricultural knowledge and for quintessentially "Cultural Revolution"-era systems of knowledge production and circulation. 